\title{
Analysis of the 2008 heavy snowfall over South China using GPS PWV measurements from the Tibetan Plateau
}

\author{
Y. Xie ${ }^{1}$, F. Wei ${ }^{2}$, G. Chen ${ }^{2}$, T. Zhang ${ }^{2}$, and L. Hu ${ }^{3}$ \\ ${ }^{1}$ Department of Atmospheric Sciences, Texas A\&M University, College Station, TX, USA \\ ${ }^{2}$ State Key Laboratory of Severe Weather, Chinese Academy of Meteorological Sciences, Beijing, China \\ ${ }^{3}$ Department of Oceanography, Texas A\&M University, College Station, TX, USA
}

Received: 22 November 2009 - Revised: 3 June 2010 - Accepted: 18 June 2010 - Published: 25 June 2010

\begin{abstract}
Four successive storms with freezing rain and snow blanketed South China from 10 January-2 February 2008 , when the precipitation increased more than $200 \%-$ $300 \%$ above the average for the corresponding period. The unusual atmospheric circulation associated with these disasters was caused by many complex physical processes, one of which was the active southern branch of currents over low latitude ocean areas which provided plenty of water vapor for South China. The ground-based GPS Precipitable Water Vapor (PWV) measurements on the Tibetan Plateau, supported by the China and Japan Intergovernmental Cooperation Program (JICA), has compensated for the lack of conventional observations of atmospheric water vapor in this area and provided a good opportunity to analyze the character of the water vapor transport in the four heavy precipitation processes. It was found that the GPS stations located on the southeastern Tibetan Plateau were on the route of the water vapor transport during 25 January-29 January and 31 January-2 February when two heavy precipitation events occurred over South China. The increasing trend from the one to two days pre-observation by the GPS stations was then associated with the heavy precipitation. Precipitation during 10 January-16 January and 18 January-22 January was significantly related to the abnormal variation of the one day preobservation by the GPS stations located on the northeastern Tibetan Plateau. This research indicates that ground-based GPS measurements are applicable to data assimilation in operational numerical models.
\end{abstract}

Keywords. Hydrology (Precipitation; Snow and ice; Transport)

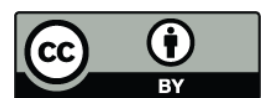

Correspondence to: $\mathrm{Y}$. Xie

(xieyupku@tamu.edu)

\section{Introduction}

The Tibetan Plateau, the largest and highest plateau in the world, has unique geologic features and plays an important role in global energy and water cycles (Flohn, 1968; Ma et al., 2006; Liu et al., 2007; Xu et al., 2008) and is also the source of the Changjiang (Yangtze River) and Huanghe (Yellow River). It serves as a transfer point for the water vapor from low latitude ocean areas to East Asian areas including the Changjiang Estuary region (Xu et al., 2003). It is crucial to understand the impact of the Tibetan Plateau on precipitation over East Asia and global climate change in terms of dynamics and thermodynamics (Tao and Ding, 1981; Wu and Zhang, 1998; Wu and Qian, 2003; Zhao et al., 2007). The lack of meteorological stations and observation of water vapor over the Tibetan Plateau has long been one of the primary difficulties in the analysis and prediction of abnormal precipitation over the Changjiang Estuary region. Recently, a complex meteorological observation system was established on the Tibetan Plateau and its surrounding eastern area. This system, as an important component of JICA, includes ground-based GPS, Automatic Weather Station (AWS) and wind speed profiler, and provides high spatial and temporal resolution PWV data. It has been proved that PWV data measured by ground-based GPS has the same accuracy as Radiosonde (Bevis et al., 1992; Rocken et al., 1997; Iwabuchi et al., 2000; Braun et al., 2001; Fujita et al., 2008; Shoji et al., 2009). Thus, the GPS PWV data under JICA has compensated for the lack of conventional observations of atmospheric water vapor on the Tibetan Plateau. It has been demonstrated that the observation of PWV can be assimilated into the Weather Research and Forecasts (WRF) model and it may significantly improve the numerical simulation and forecasting of precipitation over the downstream area of the Changjiang (Peng et al., 2009). 

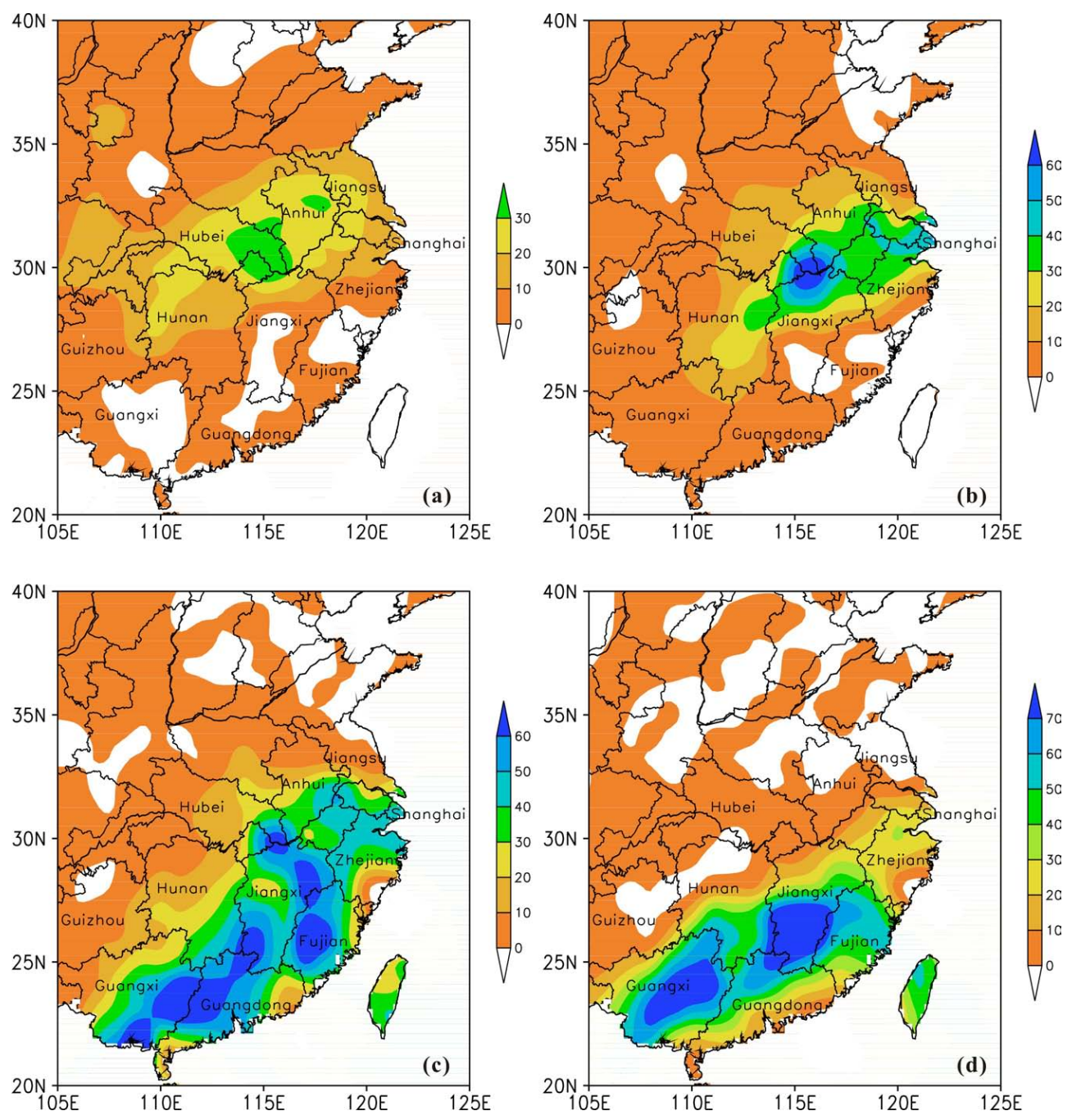

Fig. 1. Precipitation distributions of the four successive storms during (a) 10 January-16 January, (b) 18 January-22 January, (c) 25 January29 January, and (d) 31 January-2 February 2008. Units are mm.

From 10 January to 2 February 2008, South China experienced four successive storms with freezing rain and snow which are very infrequent in terms of influence area, duration, intensity, and disaster loss. According to our records, that snowfall was a once-in-50-year event which means its largest precipitation has a $2 \%$ chance of occurring in any given year. Figure 1 shows the precipitation distributions during the four successive storms. The first two heavy precipitations (Fig. 1a and b), during 10 January-16 January and 18 January-22 January, were over Anhui, Jiangsu, and Hubei which are located in the northern part of South China. The third and fourth precipitations (Fig. 1c and d) which occurred during 25 January-29 January and 31 January-2 February concentrated on the southern part of South China (specifically, Jiangxi, Hunan, and Guangxi). Overall, there was more precipitation in the third and fourth processes. The total precipitation from these four processes averaged more than
$200 \%-300 \%$ of the corresponding period. It is well known that transfer of water vapor is very important in successive precipitation events. Thus, it is interesting to analyze the influence of the water vapor over the Tibetan Plateau from those four heavy precipitation processes. This study analyzed the features of the water vapor transfer and the influence of the GPS PWV over the Tibetan Plateau on the precipitation processes by using hourly PWV from ground-based GPS stations on the Tibetan Plateau and precipitation data from AWSs in South China.

\section{Synoptic circulation and vertically integrated water vapor flux in the precipitation processes}

Based on the analysis of atmospheric circulation patterns during the snowstorms, the successive heavy precipitation over South China was caused by associated atmospheric 
circulation anomalies. Figure 2 displays the mean $500 \mathrm{hPa}$ geopotential height anomaly field observed during 10 January-2 February 2008 when positive and negative values are shown in the northern and southern areas of East Asia, respectively. The Ural Mountains were a strong positive anomaly during the heavy precipitation over South China. A steady block of high pressure in the vicinity of the Ural Mountains was propitious to the cold air from Siberia sweeping across China. A low-pressure system developed over the southern Tibetan Plateau which caused warm moist air to be continuously transferred to China with a southwesterly flow. At the same time, a strong subtropical high had extended northward with cold and warm fronts colliding and heavy precipitation occurring over the downstream area of the Changjiang. Therefore, transportation of warm, wet air to South China may have caused the successive precipitation over this area. Figure 3 shows the vertically integrated water vapor flux during the four heavy precipitation processes. The water vapor flux was computed from the NCEP/NCAR reanalysis daily average data, where the spatial resolution is $1^{\circ} \times 1^{\circ}$. The four panels of Fig. 3 represent the relative contribution of water vapor in the four precipitation processes during 10 January-16 January, 18 January-22 January, 25 January-29 January, and 31 January-2 February 2008. Figure $3 \mathrm{a}$ and $\mathrm{b}$ shows that this water vapor was mainly initiated from the Arabian Sea and the Bay of Bengal and moved with an eastward propagation of a short wave trough in the westerlies. The secondary source of the water vapor during the first two precipitation processes was the Pacific Ocean where water vapor moved westward to a strong convergence zone in South China. Figure 3a and b also indicates that the water vapor in the abovementioned movements passed through the eastern Tibetan Plateau while abundant water vapor was concentrated on the southeastern Tibetan Plateau. Thus, the water vapor over the Tibetan Plateau was a crucial source of the heavy precipitation in South China. Water vapor in the third and fourth precipitations was partially transferred by southwesterly flow through the South China Sea and partially originated over the Bay of Bengal and arrived in South China with the southwesterly flow ahead of south branch westerly troughs. It is demonstrated in Fig. $3 \mathrm{c}$ and $\mathrm{d}$ that the water vapor involved with the third and fourth precipitations also passed through the southeastern Tibetan Plateau though its origin and transferring path are different from those in the first two precipitations. Therefore, the eastern Tibetan Plateau was an important transport point for water vapor during the heavy precipitation processes over South China.

\section{GPS PWV data}

As abovementioned, during the 2008 heavy rainfall, abundant water vapor was transported to South China along with wet and warm flows. The GPS stations on the Tibetan Plateau were on the route of the water vapor transport. Figure 4 de-

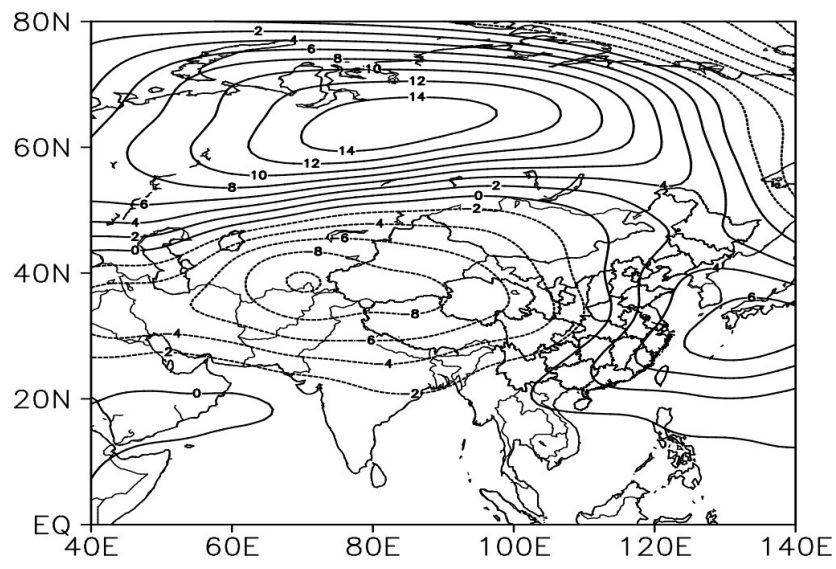

Fig. 2. Mean $500 \mathrm{hPa}$ geopotential height anomaly field during 10 January-2 February 2008. The Solid and dotted lines indicate positive and negative values, respectively.

picts the locations of the eighteen ground-based GPS stations having successful measurements during the storms and those of the twenty-four AWSs that provide precipitation data of South China.

It is known that GPS signal experiences propagation delays when traversing the ionosphere and neutral atmosphere. The ionospheric delay can be eliminated by using the dual frequencies (around 1.5 and $1.2 \mathrm{GHz}$ ) inherent in the GPS signal (Bevis et al., 1992). The Zenith Total Delay (ZTD), the delay of the neutral atmosphere, is estimated hourly using GAMIT/GLOBK v10.32 (King and Bock, 2005) and the GPS data where a sampling rate of $30 \mathrm{~s}$ and a cutoff angle of $15^{\circ}$ are applied. The ZTD can be split into Zenith Hydrostatic delay (ZHD) and Zenith Wet Delay (ZWD). The ZHD is derived using the Saastamoinen model (Saastamoinen, 1972) and measured surface pressure while the ZWD can be computed by subtracting the ZHD from the ZTD. The ZWD, having an accuracy of $1 \mathrm{~cm}$, is then converted into PWV. Measured surface temperature is employed in the conversion from ZWD to PWV. Figure 5 shows the comparison between the GPS PWV data from Mengzi, Yunnan $\left(23.37595^{\circ} \mathrm{N}\right.$, $103.38509^{\circ} \mathrm{E}$ ) and the PWV derived from radio-sounding measurements. As the radio-sounding measurements are performed two times a day at 12:00 and 24:00 UTC, they were compared with the GPS PWV data at the same time during 6 January-2 February 2008. The average bias of the two measurements is $0.358 \mathrm{~cm}$ while the standard deviations of the GPS PWV and radio-sounding measurements are 0.509 and $0.401 \mathrm{~cm}$, respectively. The mean distance between the GPS station and the radio-sounding measurement is $15 \mathrm{~km}$. Figure 5 shows that the PWV from the GPS station and radiosounding measurements agrees very well. The correlation coefficient is 0.83137 with a confidence level greater than $99.9 \%$. 
(a)

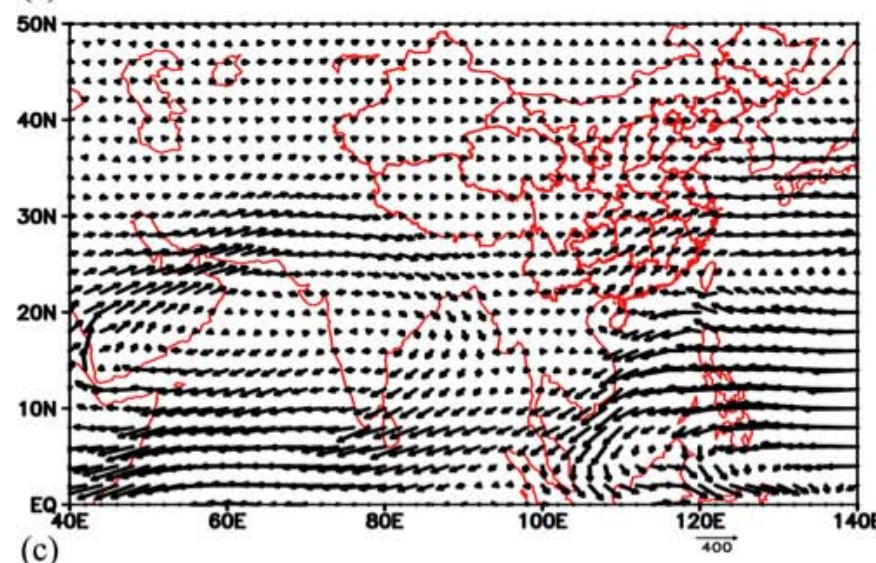

(c)

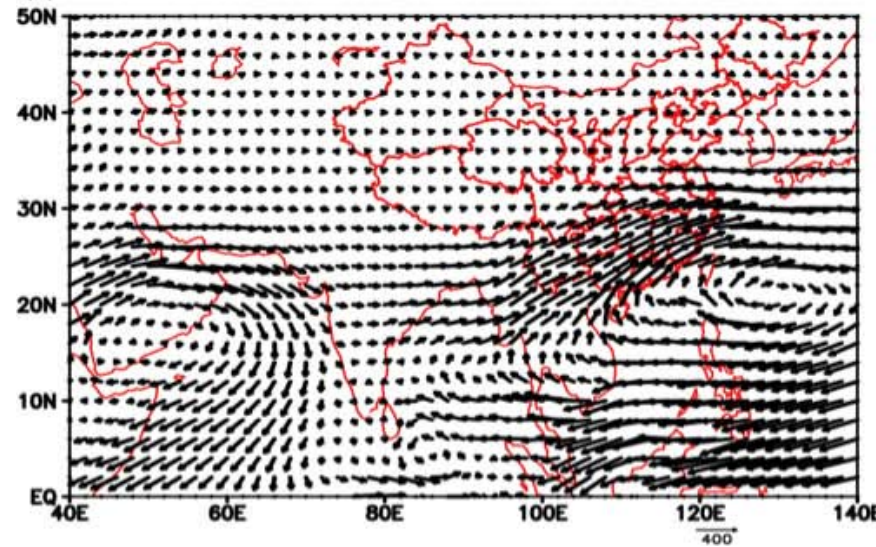

(b)

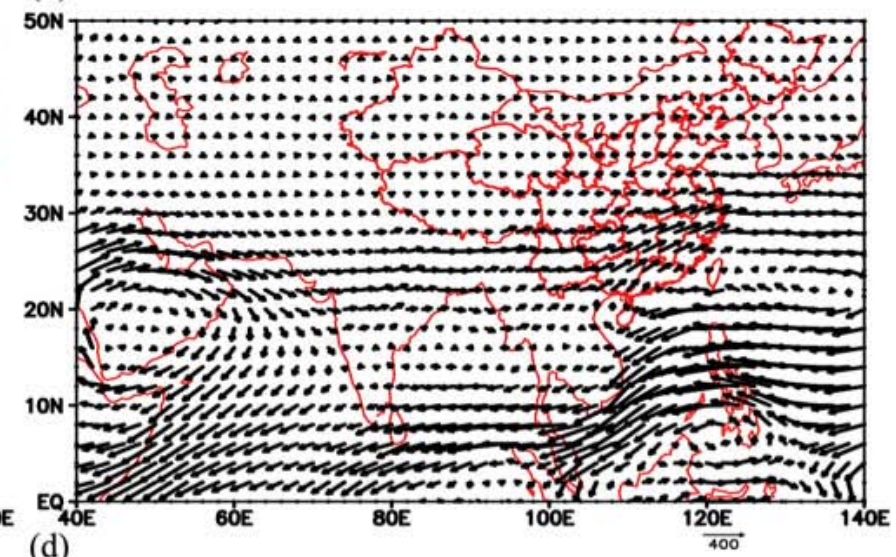

(d)

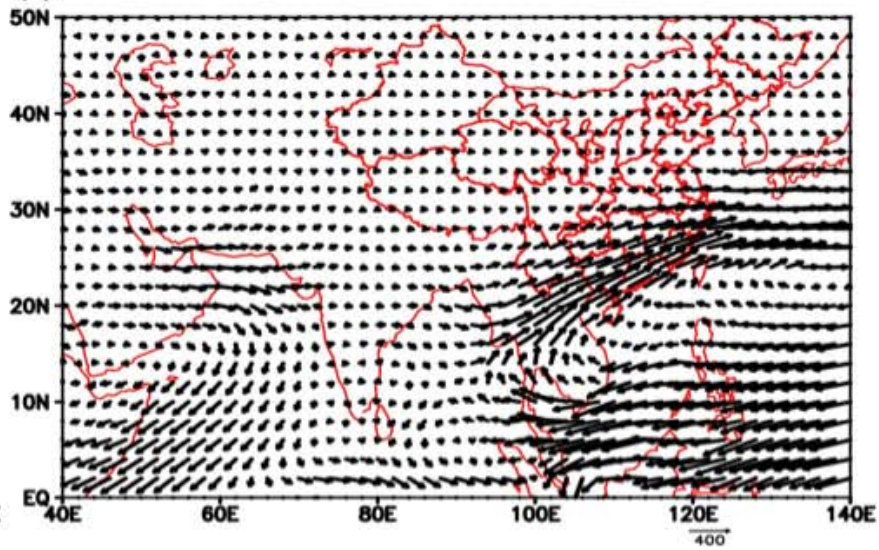

Fig. 3. Vertically integrated water vapor flux from the surface to $100 \mathrm{hPa}$ during (a) 10 January-16 January, (b) 18 January-22 January, (c) 25 January-29 January, and (d) 31 January-2 February 2008. Units are kg/(m s).

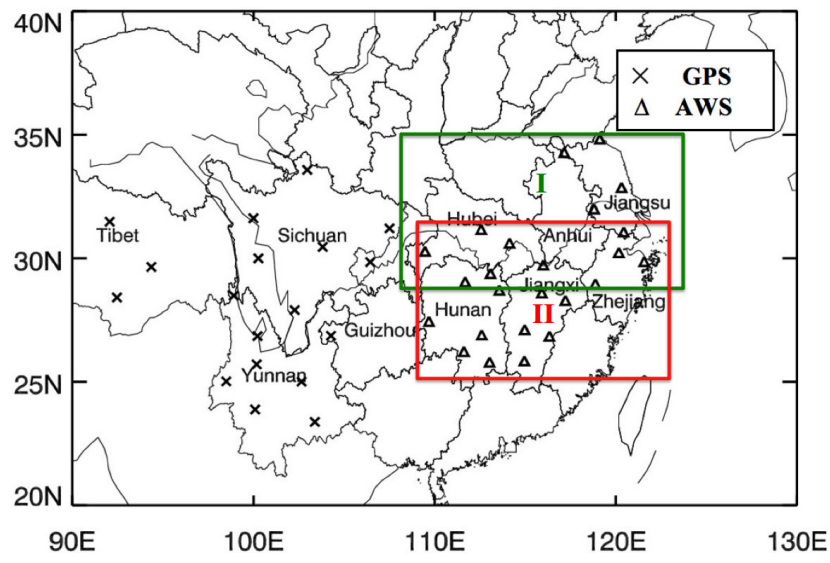

Fig. 4. Eighteen GPS stations on the Tibetan Plateau and Twentyfour AWSs in South China.

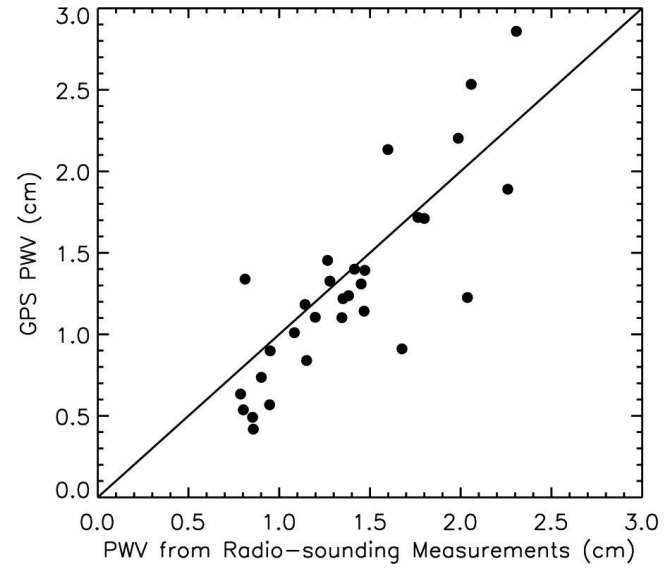

Fig. 5. Comparison between GPS PWV data from Mengzi, Yunnan $\left(23.37595^{\circ} \mathrm{N}, 103.38509^{\circ} \mathrm{E}\right)$ and the PWV derived from airborne measurements. 


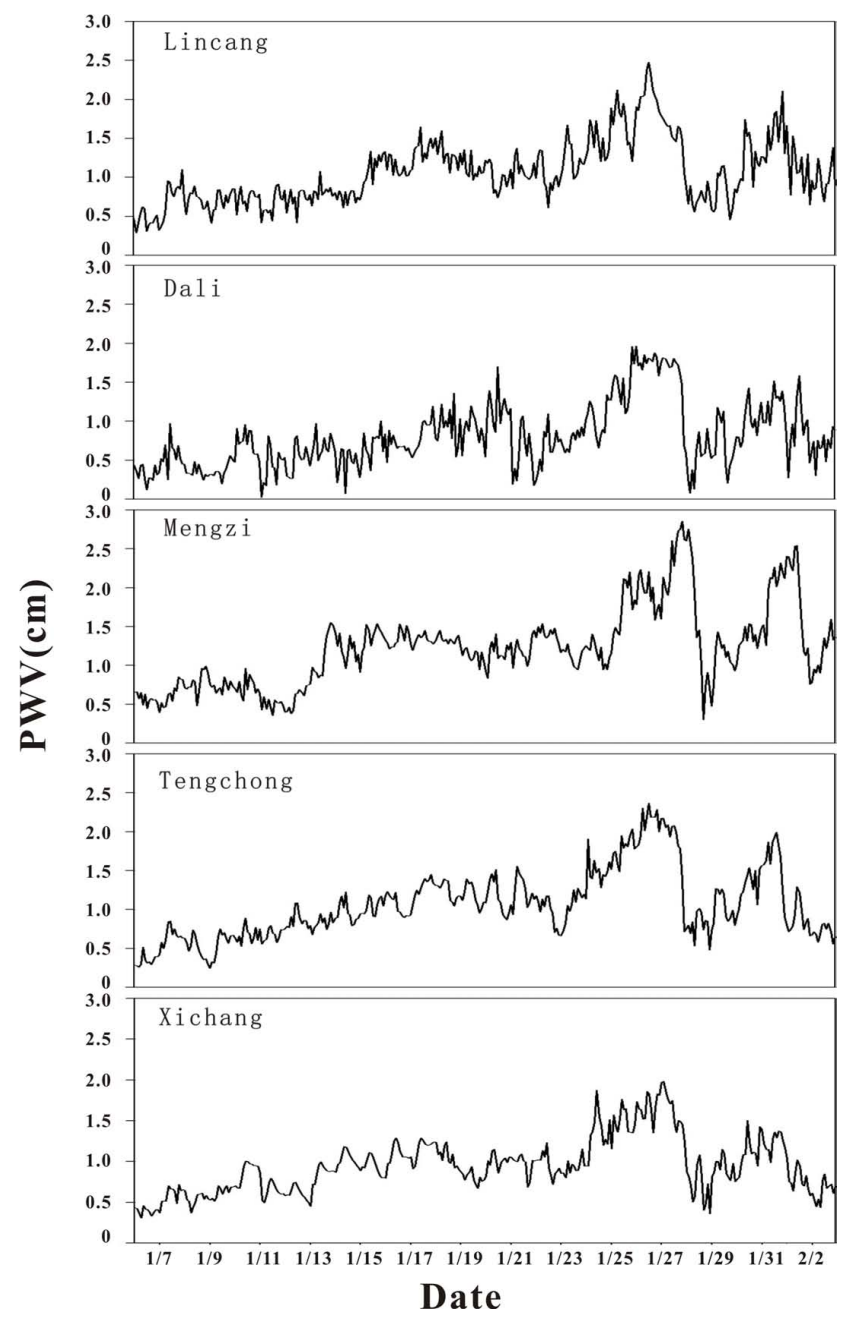

Fig. 6. Hourly GPS PWV during 6 January-2 February 2008 from Lincang, Yunnan $\left(23.88154^{\circ} \mathrm{N}, 100.08996^{\circ} \mathrm{E}\right)$; Dali, Yun$\operatorname{nan}\left(25.70729^{\circ} \mathrm{N}, 100.17593^{\circ} \mathrm{E}\right)$; Mengzi, Yunnan $\left(23.37595^{\circ} \mathrm{N}\right.$, 103.38509 $\left.{ }^{\circ} \mathrm{E}\right)$; Tengchong, Yunnan $\left(25.01855^{\circ} \mathrm{N}, 98.49748^{\circ} \mathrm{E}\right)$; and Xichang, Sichuan $\left(27.90411^{\circ} \mathrm{N}, 102.26766^{\circ} \mathrm{E}\right)$.

\section{Analysis of the heavy precipitation over South China using GPS PWV measurements from the Tibetan Plateau}

Figure 6 shows the hourly PWV data from five GPS stations during 6 January-2 February 2008. By comparing with Fig. 1, we found that the precipitation over South China increased with the GPS PWV. Specifically, the precipitation in the third and fourth processes substantially increased when the GPS PWV achieved its maximum value.

In this section, we study the relationship between the GPS PWV and the heavy precipitation over the Tibetan Plateau and South China, respectively. Because abnormal weather is related to atmospheric disturbances at various scales of time and space, the Empirical Orthogonal Function (EOF) analysis is employed to find time series and spatial patterns of the (a)

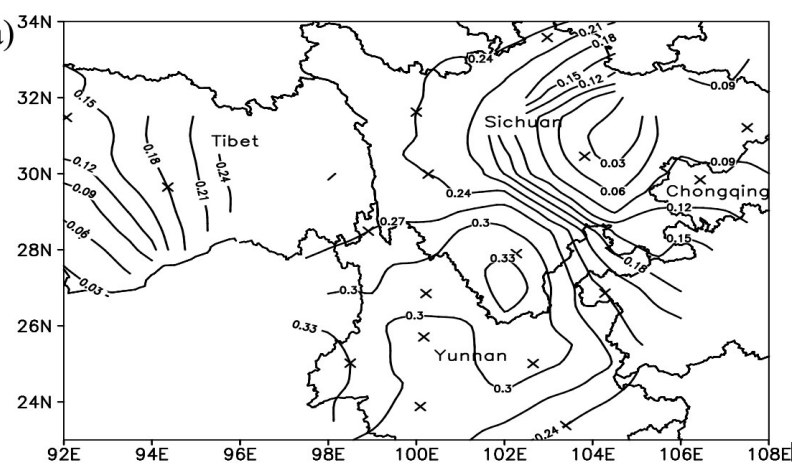

(b)

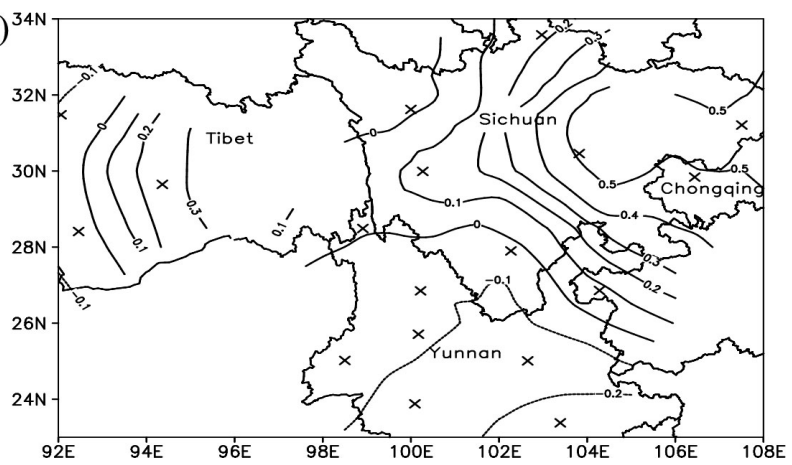

Fig. 7. The (a) first and (b) second eigenvectors of GPS PWV over the Tibetan Plateau during 6 January-2 February 2008. The solid and dotted lines indicate positive and negative values, respectively.

GPS PWV. Using EOF analysis, we extracted the large-scale signal of the PWV from the low-order EOFs. At the same time, the water vapor transports can be distinguished based on their orientations and the origins of the moisture sources. The hourly PWV data during 6 January-2 February 2008, was standardized and decomposed into terms of Empirical Orthogonal Functions (EOF) to describe the spatial and temporal variability. The first two eigenvectors explain $62 \%$ of the total variance, which indicates that they describe the major spatial distribution of the GPS PWV data over the eastern Tibetan Plateau. Figure 7a shows the first eigenvector that explains $45 \%$ of the total variance. It suggests that the spatial distribution of the GPS PWV data was quite stable during the heavy precipitation over South China. Two largest variable centers of GPS PWV are found in eastern Tibet and Yunnan. The second eigenvector (see Fig. 7b) explains 17\% of the total variance and indicates that eastern Sichuan and Yunnan have opposite variance for the spatial distribution of the GPS PWV. Figure $7 b$ indicates that the other variable center of GPS PWV is located on the northeastern Tibetan Plateau. The averaged altitudes of the GPS stations in eastern Tibet, Yunnan and eastern Sichun are 3300 m, 2000 m, and 500 m, respectively. Thus, EOF analysis can be also used to distinguish the GPS PWV in terms of its variable centers and the altitudes of the GPS stations. It also reveals that the distributions of PWV in Fig. 7a and b correspond with the water 

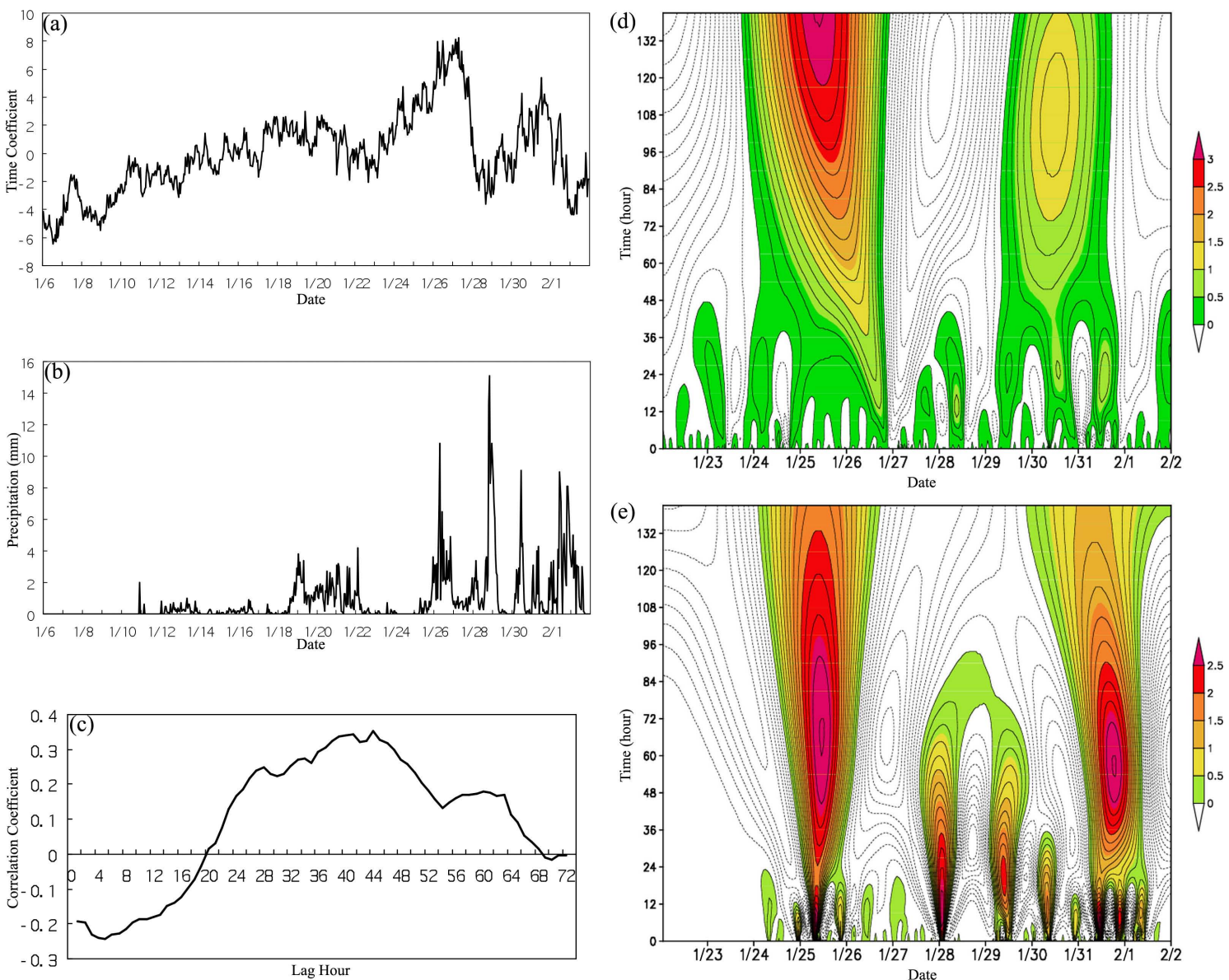

Fig. 8. (a) Time coefficient associated with the first eigenvector of the GPS PWV over the southeast of the Tibetan Plateau. (b) Hourly precipitation over area II. (c) Correlation coefficients of the second eigenvector of the GPS PWV over the southeastern Tibetan Plateau and precipitation over area II with 0-72 h lags. (d) Time-frequency representation of the PWV from Dali GPS station. (e) Time-frequency representation of precipitation from Ganzhou AWS.

vapor transport shown in Fig. 3c and d and 3a and b, respectively.

This study analyzed the effect of the two variable centers of GPS PWV on the heavy precipitation over South China. As described in the introduction, the first two heavy precipitation events happened in the northern part of South China while the third and fourth precipitations were detected in the southern part of South China. Based on the spatial distribution of the precipitation, we hereafter address the precipitating areas as areas I and II (see Fig. 4) that are associated with the first two and last two precipitations, respectively. Fourteen and twenty AWSs, respectively, are located in these two areas.

Based on the theory of EOF analysis, the time series of expansion coefficients associated with the first eigenvector of GPS PWV data represents the variation of the PWV over time on the southeastern Tibetan Plateau during the heavy precipitation. It is seen from Fig. 8a that the PWV over the southeastern Tibetan Plateau did not substantially increase during the first two precipitations. However, during the third and fourth precipitations, the PWV over the southeastern Tibetan Plateau significantly increased which strongly corresponds with the precipitation over area II (see Fig. 8b). Figure $8 \mathrm{~b}$ shows the hourly precipitation given from the twenty AWSs of area II, where heavy precipitation occurred intermittently during 25 January-2 February. From the comparison between Fig. 8a and b, it is not difficult to deduce that the maximum values of the PWV over the southeastern Tibetan Plateau were above the precipitation peaks for area II. Shown in Fig. 8c are the correlation coefficients of the PWV over the southeastern Tibetan Plateau and the precipitation over area II with $0-72 \mathrm{~h}$ lags. From Fig. 8c, the PWV over the southeastern Tibetan Plateau is strongly correlated with the precipitation with a $24-48 \mathrm{~h}$ lag giving confidence greater than $99.0 \%$. Therefore, 1-2 days ahead of PWV over the southeastern Tibetan Plateau can substantially denote the precipitation over South China. To verify this conclusion, we applied wavelet transform to hourly PWV 
from Dali GPS station (in Yunnan) and precipitation from Ganzhou AWS (in Jiangxi) during the third and fourth precipitation events (23 January-2 February) where the Dali GPS station and Ganzhou AWS represented the GPS stations on the southeastern Tibetan Plateau and the AWSs on area II, respectively. Wavelet transform is a powerful tool to describe the subgrid-scale variability of signals in the assumption of a known coarse-scale field (Kumar, 1996). In this study, we used wavelet transform to separate physical meaningful signal components from background noise and analyze the relationship between the variation in the PWV and the precipitation over the Tibetan Plateau and South China, respectively. Figure $8 d$ and e are the time-frequency representations of the PWV from Dali GPS station and the precipitation from Ganzhou AWS, respectively. It was found that the variation trends of the PWV and precipitation are very similar. The PWV formed slightly ahead of the precipitation, particularly during the fourth precipitation when the increase of the PWV was 1-2 days ahead of the precipitation. Overall, the results shown in Fig. 8 indicate that the southeastern Tibetan Plateau was on the route of the water vapor transport associated with the third and fourth heavy precipitations.

The time series of expansion coefficients associated with the second eigenvector of GPS PWV data (Fig. 9a) represents the variation of PWV over the northeastern Tibetan Plateau during the heavy precipitation. Figure $9 \mathrm{~b}$ shows the precipitation over area I. It is clearly evident that the PWV over the northeastern Tibetan Plateau closely corresponds with the first two heavy precipitations. The PWV started to increase on 9 January when the first precipitation formed about $24 \mathrm{~h}$ later. Then both the PWV and precipitation over area I achieved their maximum values during 11 January-12 January. Moreover, the PWV showed a growing trend with the coming of the second heavy precipitation on 18 January. It is suggested that other water vapor sources may also have contributed to the second precipitation process because of the smaller PWV increase compared to the first precipitation. Figure 9c shows the correlation coefficients of the second eigenvector of GPS PWV and the precipitation over area I with $0-72 \mathrm{~h}$ lags. The relationship between the PWV over the northeastern Tibetan Plateau and the precipitation with a $0-24 \mathrm{~h}$ lag arrives at the largest confidence level - greater than $99.0 \%$. However, the duration of the relationship between the PWV over the northeastern Tibetan Plateau and the precipitation over area I was not as long as the PWV over the southeastern Tibetan Plateau and the precipitation over area II. This may have occurred partially because the center of the PWV over the northeastern Tibetan Plateau was closer to the precipitation area than the southeastern Tibetan Plateau. Of course, differences in the dynamical and thermodynamical processes could be another reason that led to the correlation between PWV and precipitation with a diverse lag time.
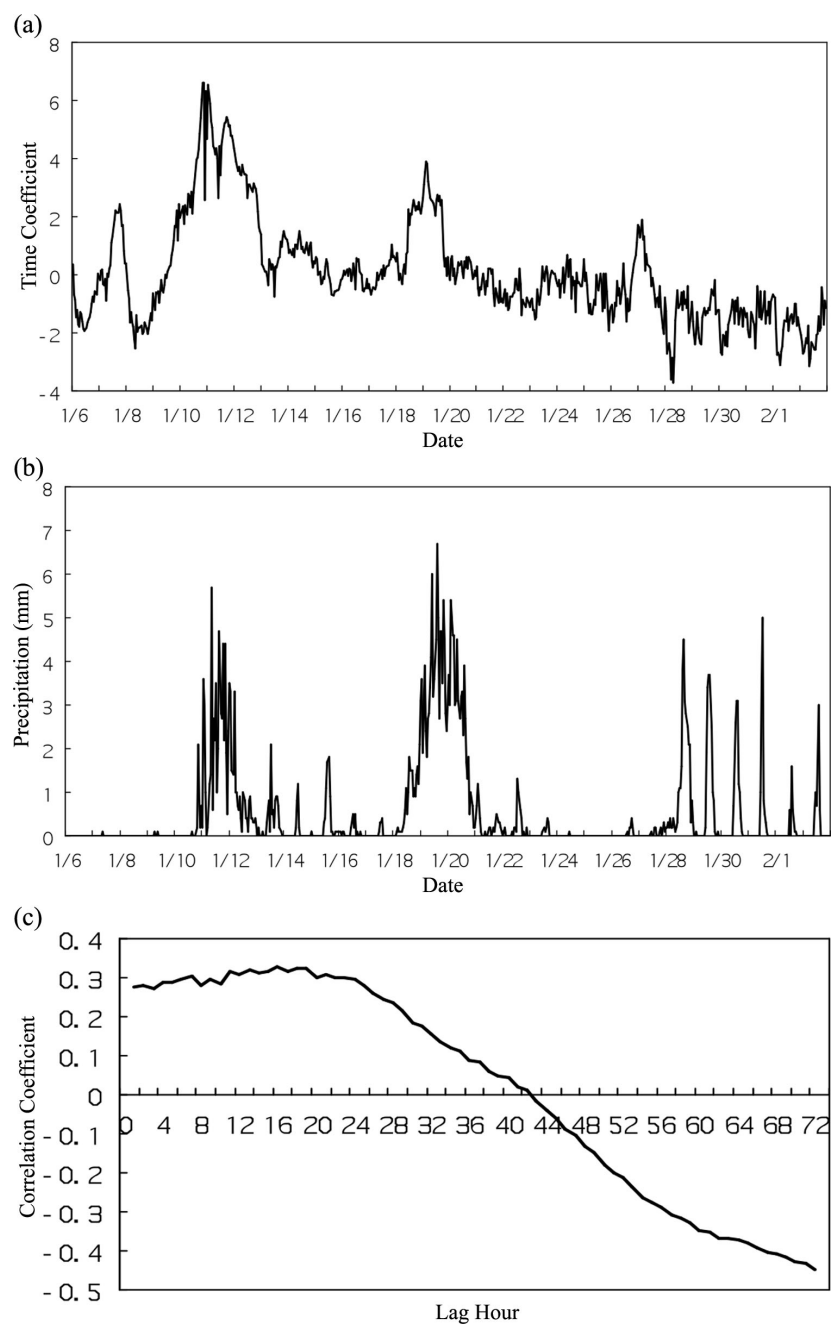

Fig. 9. (a) Time coefficient associated with the second eigenvector of the GPS PWV over the northeastern Tibetan Plateau. (b) Hourly precipitation over area I. (c) Correlation coefficients of the second eigenvector of the GPS PWV over the northeastern Tibetan Plateau and precipitation over area I with $0-72 \mathrm{~h}$ lags.

\section{Conclusions}

The area east of the Tibetan Plateau was one of the important transport points of water vapor during the 2008 heavy snowfall over South China. It became possible to analyze the water vapor transport during the precipitation by taking advantage of PWV data from ground based GPS stations on the Tibetan Plateau. Using the EOF analysis method, we divided the eighteen GPS stations into two GPS PWV groups located on the southeastern and northeastern Tibetan Plateau. We found that the southeastern Tibetan Plateau was on the route of the water vapor transport during the third and fourth heavy precipitations. The increased trend from the one to two days pre-observation of PWV over the southeastern Tibetan Plateau could be a strong indication for heavy precipitation 
over area II. The northeastern Tibetan Plateau was one of the important transport points for the water vapor during the first two heavy precipitations. The abnormal variation of the one day pre-observation for this PWV group had very good correspondence to the heavy precipitation over area I. It is concluded that the variation in GPS PWV over the Tibetan Plateau could be an important reference for the prediction of precipitation over South China. Because the GPS stations were recently established and very limited data is available due to technical reasons, the discussion above was given based on the analysis of the four heavy precipitation events in 2008. It is known that heavy precipitation is usually affected by numerous meteorological factors and high PWV is only one of them. However, our study has accessed the potential for using the GPS PWV measurements as initial conditions to improve the operational numerical models.

Acknowledgements. This research was supported by the National Natural Science Foundation of China (grant 40975044), JICA and the Key Technologies R\&D Program of China (grant 2009BAC51B04).

Topical Editor P. Drobinski thanks one anonymous referee for her/his help in evaluating this paper.

\section{References}

Arneodo, A., Grasseau, G., and Holschneider, M.: Wavelet transform analysis of invariant measures of some dynamical systems, in: Wavelets: Time-Frequency Methods and Phase Space, edited by: Combes, J. M., Grossmann, A., and Tchamitchian, P., pp. 183-196, Springer-Verlag, New York, 1989.

Bevis, M., Businger, S., Herring, T. A., Rocken, C., Anthes, R. A., and Ware, R. H.: GPS Meteorology: Remote Sensing of Atmospheric Water Vapor Using the Global Positioning System, J. Geophys. Res., 97, 15787-15801, 1992.

Braun, J., Rocken, C., and Ware, R.: Validation of line-of-sight water vapor measurement with GPS, Radiat. Sci., 36, 459-472, 2001.

Flohn, H.: Contributions to a meteorology of the Tibetan Highlands, pp. 120, Colorado State University, Fort Collins, CO, 1969.

Fujita, M., Kimura, F., Yoneyama, K., and Yashizaki, M.: Verification of precipitable water vapor estimated from shipborne GPS measurements, Geophys. Res. Lett., 35, L13803, doi:10.1029/2008GL033764, 2008.

Iwabuchi, T., Naito, I., and Mannoji, N.: A comparison of global positioning system retrieved precipitable water vapor with the numerical weather prediction analysis data over the Japanese islands. J. Geophys. Res., 105, 4573-4585, 2000.

King, R. W. and Rock, Y.: Documentation for the GAMIT GPS analysis software, version 10.2, Massachusetts Institute of Technology, Cambridge, Massachusetts, 2005.
Kumar, P.: Role of coherent structures in the stochastic-dynamic variability of precipitation, J. Geophys. Res., 101, 26393-26404, 1996.

Liu, Y., Bao, Q., Duan, A., Qian, Z., and Wu, G.: Recent progress in the impact of the Tibetan Plateau on climate in China, Adv. Atmos. Sci., 24, 1060-1076, 2007.

Ma, Y., Zhong, L., Su, Z., Ishikawa, H., Menenti, M., and Koike, T.: Determination of regional distributions and seasonal variations of land surface heat fluxes from Landsat-7 Enhanced Thematic Mapper data over the central Tibetan Plateau area, J. Geophys. Res., 111, D10305, doi:10.1029/2005JD006742, 2006.

Meyer, Y.: Wavelets and applications: Proceedings of the International Conference, Research Notes in Applied Mathematics, vol. 20, Marseille, France, 1989.

Peng, S. Q., Xu, X. D., Shi, X. H., Wang, D. X., Zhu, Y. X., and $\mathrm{Pu}$, J. J.: The early-warning effect of assimilation of the observation over the large-scale slope of the "world roof" on its downstream weather forecasting, Chinese Science Bulletin, 54, 706710, 2009.

Rocken, C., Hove, T. V., and Ware, R.: Near real-time GPS sensing of atmospheric water vapor, Geophys. Res. Lett., 24, 3221-3224, 1997.

Saastamonien, J.: Atmospheric correction for troposphere and stratosphere in radio ranging of satellites, Geophysics Monograph series, vol. 15, edited by: Henriksen, S. W., Mancini, A., and Chovitz, B. H., Washington, D.C., American Geophysical Union, 1972.

Shoji, Y., Kunii, M., and Saito, K.: Assimilation of nationwide and global GPS PWV data for a heavy rain event on 28 July 2008 in Hokuriku and Kinki, Japan, SOLA, 5, 45-48, 2009.

Tao, S. and Ding, Y.: Observational evidence of the influence of the Qinghai-Xizang (Tibet) Plateau on the occurrence of heavy rain and severe convective storms in China, B. Am. Meteorol. Sci, 62, 23-30, 1981.

Wu, G. and Zhang, Y.: Tibetan Plateau forcing and the timing of the monsoon onset over South Asia and the South China sea, Mon. Weather Rev., 126, 913-927, 1998.

Wu, T. and Qian, Z.: The relation between the Tibetan winter snow and the Asian summer monsoon and rainfall: An observational investigation, J. Climate, 16, 2038-2051, 2003.

Xu, X., Miao, Q., Wang, J., and Zhang, X.: The water vapor transport model at the regional boundary during the Meiyu period, Adv. Atmos. Sci., 20, 333-342, 2003.

Xu, X., Lu, C., Shi, X., and Gao, S.: World water tower: An atmospheric perspective, Geophys. Res. Lett., 35, L20815, doi:10.1029/2008GL035867, 2008.

Zhao, P., Zhou, Z., and Liu, J.: Variability of Tibetan spring snow and its associations with the hemispheric extra-tropical circulation and East Asian summer monsoon rainfall: An observational investigation, J. Climate, 20, 3942-3955, 2007. 